\title{
GESTOS HUMANOS, GESTOS URBANOS: MEMÓRIAS COTIDIANAS DA PAISAGEM COLONIAL ALAGOANA
}

\author{
HUMAN GESTURES, URBAN GESTURES: DAILY MEMORIES OF ALAGOAS COLONIAL \\ LANDSCAPE
}

\section{SILVA, Maria Angélica da}

Profa. Dra. do Departamento de Arquitetura e Urbanismo da UFAL-Brasil; Coordenadora do Grupo de Pesquisa Estudos da Paisagem-UFAL.E-mail: mas@fapeal.br

\section{OLIVEIRA, Roseline}

Profa. do Centro Federal de Educação Tecnológica de Alagoas; Doutoranda do PPGAU da UFBA-Brasil; Pesquisadora do Grupo de Pesquisa Estudos da Paisagem-UFAL. E-mail: roselineoliveira@gmail.com

\section{MOTA, Melissa}

Mestra do PPG em Desenvolvimento e Meio Ambiente da UFAL-Brasil; Pesquisadora do Grupo de Pesquisa Estudos da Paisagem-UFAL. E-mail: motamelissa@yahoo.com.br

\section{RESUMO}

Partindo do pressuposto de que a paisagem carrega um conteúdo material e imaterial ao longo do processo de sua formação, esta comunicação trata de uma determinada região do litoral de Alagoas. Tal região foi registrada no período colonial nas telas e mapas elaborados pelos holandeses quando ocuparam o nordeste brasileiro, que foi confrontado com registros coletados no mesmo local na atualidade. No passado, a região foi cenário do episódio canibalístico envolvendo o bispo Pero Fernandes Sardinha. Contudo, ao invés das grandes ações históricas, esta comunicação enfoca gestos humanos aparentemente ignoráveis, mas essenciais, quando se leva em conta as relações humanas que, na verdade, constituem as razões de ser das paisagens.

Palavras-chave: Paisagem, patrimônio imaterial, gestos comunitários.

\begin{abstract}
Considering that the landscape loads material and immaterial contents when observed during the long process of its formation, this paper deals with an area located in the Alagoas-Brazil seashore that was registered in the colonial period in canvases and maps made by the Dutch during its ocupation of the Brazilian Northeast. This material was confronted with contemporary registers taken in the same place. In the past, the region was the scenery for a ritual of cannibalism evolved the bishop Pero Fernandes Sardinha. Instead of focusing on these great historical facts, this paper aims to observe the human gestures, apparently disregarded but, in truth, the real basis of any landscape.
\end{abstract}

Key words: Landscape, immaterial patrimony, communitarian gestures.

\section{Construindo paisagens}

Paisagens carregam em si a produção humana e os eventos que se desenrolam durante sua construção. No cerne do seu processo de formação, situa-se o homem em comunidade, que atua na dinâmica de novas cenas espaciais, muitas vezes construídas num movimento de interação com cenários previamente herdados. Nessa mistura de tempos, a paisagem se consolida em meio a sucessivas construções, acontecimentos e atos, conduzindo ao surgimento de novas expressões, materiais e imateriais, dialogando, sobrepondo e/ou destruindo as permanências preexistentes. 
Como em um palimpsesto, as manifestações humanas vão se imprimindo na paisagem, resultantes de uma elaboração intelectual a que se somam cognições, mitos, desejos, medos e lembranças. Portanto, a construção e a percepção da paisagem constituem uma condição variável de acordo, entre outros aspectos, com nossos princípios e conhecimento.

A possibilidade de entender o gesto urbano por uma óptica mais ampla, além dos planos da técnica, desperta-nos para a sua compreensão da como um sistema complexo de relações entre pessoas e o espaço. Nessa perspectiva, pode-se considerar que o cenário físico da cidade constitui-se também a partir de aspectos subjetivos e que um olhar sobre a paisagem edificada pode revelar valores patrimoniais não reconhecidos ou memórias adormecidas.

Partindo deste ponto de vista a respeito da paisagem', que assim se configura não apenas como a base natural onde se insere a intervenção humana ao mesmo tempo em que também não se coloca como antítese do edificado, mas que generosamente o abarca, nesta comunicação pretendemos analisar os pressupostos da formação de um determinado recorte do território alagoano. Este recorte foi selecionado entendendo-se que seu cenário físico permite o conhecimento de uma memória paisagística e o desvendamento de elementos identitários significativos. É no sentido de repertoriar os seus aspectos visíveis e invisíveis que se desenvolve esta proposta de reflexão sobre o patrimônio material e imaterial desta área situada no extremo sul de Alagoas. Marcada pelos processos iniciais da própria ocupação das terras brasílicas, ao ter servido de cenário para o emblemático acontecimento canibalístico relacionado ao bispo D. Pero Fernandes Sardinha, trata-se da região onde estão localizados hoje os municípios de Coruripe, Jequiá e Poxim.

Esta região também foi cenário de um outro fato bastante significativo da história colonial brasileira, que ocorreu no século XVII: foi invadida pelos holandeses. Além dos feitos da guerra, das questões econômicas, políticas e identitárias relacionadas a este episódio, cabe salientar a rica produção cultural legada pelos holandeses. Movidos por um outro conceito de empreitada colonial, à Companhia das Índias interessava conhecer as regiões que passavam a seu domínio. No caso do Brasil, esta atitude toma uma outra proporção com a vinda de João Mauricio de Nassau, que chega na condição de administrador, imbuído da missão de extrair da colônia conteúdos que alimentassem suas intenções humanistas de conhecer, colecionar e classificar os repertórios do mundo.

Desse momento foram produzidas, sob sua tutela, imagens, objetos, escritos fragmentos da história que venceram o tempo e conservados durante um longo tempo em arquivos nacionais e internacionais, que hoje se fazem accessíveis, proporcionando fontes privilegiadas para o estudo da história da paisagem nordestina².

Por outro lado, buscando estes lugares que serviram de base para a grande coleta realizada pelos holandeses, é possível perceber neles, fragmentos de longa duração, concretos e imaginários, que ainda pontuam tais lugares. Assim, localidades que à primeira vista configuram-se como povoados incipientes, com ruas indefinidas, casario singelo, habitados por pessoas simples, guardam evidências de um passado distante que este trabalho buscou repertoriar.

Nessa perspectiva, as discussões apresentadas nesta comunicação buscam identificar nestas paisagens, permanências correspondentes à memória dos primeiros momentos da formação territorial alagoana. Em outras palavras, as marcas destas memórias estão expressas na paisagem, que por sua vez, se constitui através destas memórias.

Assim, enquanto produto da ação humana, o recorte em estudo apresenta talvez com mais riqueza que outros, uma dimensão histórico-cultural constituída de um num mosaico de estórias e histórias que se acumularam ao longo do tempo e que, nesta comunicação, procura-se analisar na sua dimensão concreta e nos aspectos relativos ao imaginário. Trata-se de uma pesquisa ainda em andamento ${ }^{3}$, cujos primeiros resultados, porém, confirmam as bases de sua hipótese. 


\section{Observando gestos humanos na paisagem alagoana}

Nos primeiros séculos coloniais, as terras do litoral sul de Alagoas vão sendo paulatinamente esvaziadas das povoações Caetés, após a morte do bispo D. Pero Fernandes Sardinha. Assim, esta região entra para a História do Brasil marcada pela prática do canibalismo e pelos conflitos entre as populações nativas e os colonizadores. Além disto, ainda no contexto dos primeiros séculos de colonização, como se viu, na época constituindo-se como território pertencente à Capitania de Pernambuco, esta parte do atual Estado de Alagoas participou ativamente do contexto da invasão holandesa, estando na rota que ligava a sua sede administrativa holandesa, em Recife, ao extremo sul das terras ocupadas, cujo limite era o Rio São Francisco.

Desde o ano de 2000, o Grupo de Pesquisa Estudos da Paisagem ${ }^{4}$ trabalha com estas fontes holandesas seiscentistas, que, no caso da pesquisa que embasa esta comunicação, partiu da constatação de que esses registros não deixavam escapar as cenas do cotidiano nordestino, traduzindo-se em fonte de informações para a investigação acerca de vários aspectos da história das mentalidades da região, difíceis de serem encontradas nos documentos escritos. Contando na atualidade, com os recursos da linguagem da informática, através de programas gráficos, confirmou-se a partir da análise mais detalhada destas fontes, a riqueza que seus detalhes traziam em termos de informação.

Foi a partir desta constatação que o trabalho foi montado, cruzando os recortes iconográficos extraídos do material seiscentista e evidências buscadas em levantamentos de campo. Assim, está sendo possível construir um panorama de procedimentos relacionados às manifestações materiais e imateriais que foram transmitidas de geração em geração através de mais de três séculos, aferindo a sua continuidade e a sua importância histórica. Estas práticas certamente estão permeadas pela diversidade cultural que caracterizou a ocupação do Nordeste como um todo, e identificará possivelmente os traços da presença da população indígena, que, como se viu, teve sua origem mais remota registrada pela literatura como vinculada às tribos Caetés.

Cabe lembrar que esta investigação também só se torna possível pela riqueza e pela longevidade do patrimônio imaterial alagoano, que, pouco amparado pelas instituições e escassamente tomado enquanto objeto de estudo, resiste ao tempo graças à sua íntima ligação com a existência quotidiana dos habitantes. Além disto, possivelmente este registro trará também contribuições sobre a presença africana na região que alcançou sua evidência histórica mais forte no quilombo de Palmares, ao qual o material holandês também se refere. Dentre as fontes históricas que estão sendo utilizadas para embasar o trabalho, destaca-se o papel de importantes divulgadores dos saberes alagoanos, como é o caso de Théo Brandão, cujos trabalhos outrora publicados estão sendo fundamentais neste projeto, bem como o rico acervo por ele reunido, hoje abrigado no museu que leva o seu nome. Além disto, há de se salientar também os trabalhos fundamentais de José Aloísio Brandão Vilela e Manuel Diegues Júnior, que, dentro do tema do "folclore", conferiam voz às camadas anônimas da sociedade nordestina.

Além da questão da própria história do ocaso da presença Caeté na região, que não afasta também a atenção aos remanescentes da cultura indígenas em geral, observa-se algumas permanências que chegam através das chaves do saber fazer, do celebrar e do expressar no cotidiano dos habitantes. Para além de constituírem-se num convite à participação comunitária na construção da "escrita" da sua própria história a partir da coleta das falas e memórias dos moradores, os estudos abordados no projeto e apresentados nessa comunicação pretendem contribuir para a implementação de uma política do inventário dos bens materiais vinculados a estas memórias.

Para isto, os argumentos sustentam-se em evidências que se situam nas duas pontas do recorte temporal adotado no trabalho: a contemporaneidade e o contexto seiscentista. Nos dias de hoje, ainda é possível encontrar nas pequenas cidades ou povoados que conformam o recorte 
geográfico do projeto, ou seja, Coruripe, Pontal de Coruripe, Poxim e Jequiá, esta memória sobre os tempos coloniais que se evidencia não apenas no discurso sobre fatos históricos, mas também em uma série de práticas que venceram os séculos.
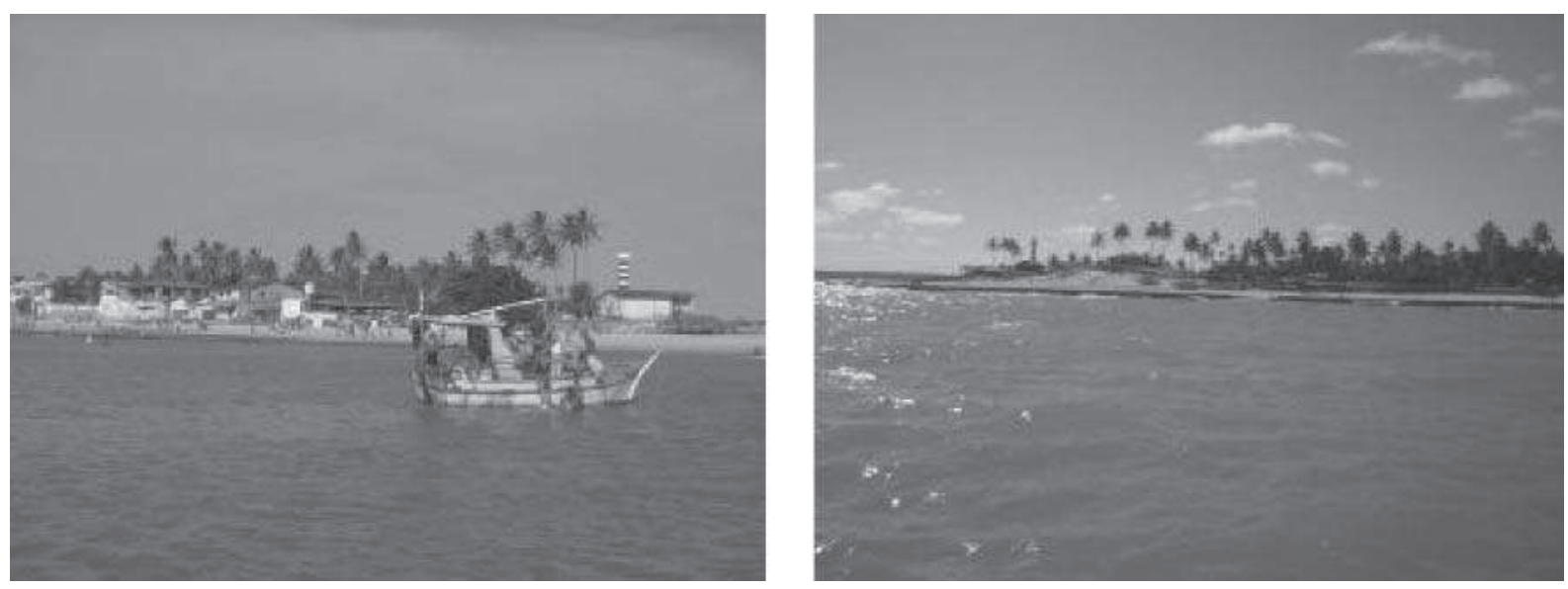

Imagens de Pontal de Coruripe

Fonte: Arquivo do Grupo de Pesquisa Estudos da Paisagem

Algumas delas relacionam-se com o saber fazer, como por exemplo, hábitos vinculados ao plantio de diversas culturas de subsistência à construção da casa, à pesca, desde a produção das ferramentas e utensílios até a execução dos trabalhos propriamente ditos, e efetivam-se envolvendo cantorias, versos e celebrações comunitárias. Estas práticas estão seriamente ameaçadas de perda e exigem um mapeamento e uma catalogação imediata.

Apesar de compartilhar com os portugueses o afã pela exploração e pelo lucro, a Companhia das Índias necessitava, para manter a colônia, conhecê-la em seus pormenores. Assim, os remanescentes do período holandês não se resumiram apenas aos relatórios relativos à administração e à guerra, mas envolveram também a catalogação da paisagem natural e edificada da colônia. Esta catalogação se dá em base literária, como também iconográfica: são mapas, vistas, desenhos gráficos, pinturas dos mais variados gêneros e um levantamento das espécies da flora e fauna minuciosamente desenhados.

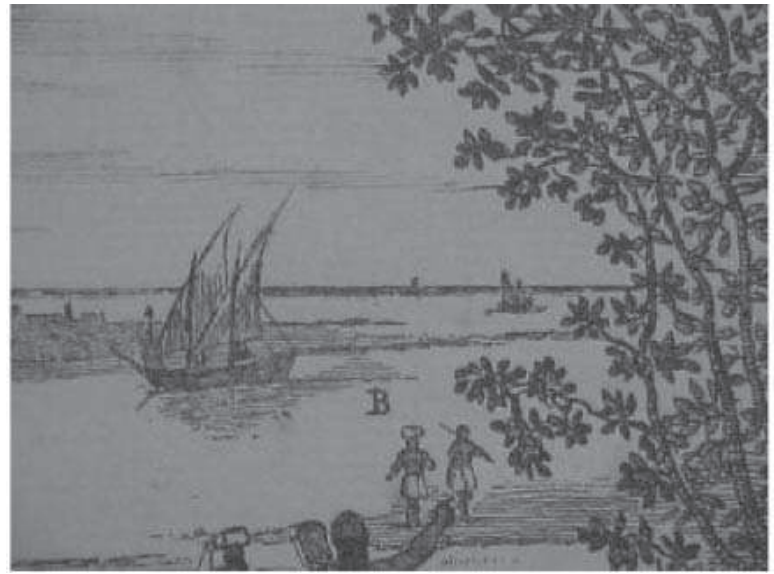

Detalhe de uma das telas de Frans Post, mostrando os barcos a vela

Fonte: BARLÉUS, 1674, disponível no acervo do IHGAPE

Embora tenha sido produzido pelas missões holandesas, onde se destaca a contribuição de Frans Post, Albert Eckhout, Guilherme Piso, George Marcgrave, Golijath, Vingbonns e outros, 
dão visibilidade ao final, às práticas conduzidas por portugueses, pelos nativos e pelos grupos advindos da África, na cena do Novo Mundo.

\section{Gestos humanos: uma camada paisagística}

Apesar do território geográfico alagoano ter servido de "cenário" para fatos de grande significação histórica recebeu pouca atenção com relação a estudos documentais, o que nos traz a urgência de um mapeamento que abarque a riqueza das práticas encontradas nas localidades.

Observa-se na região, ainda nos dias atuais, a constante presença da taipa e de hábitos tradicionais, além do uso de alimentos e receitas tradicionais que são apresentados no material iconográfico seiscentista. Assim, há uma sinalização de que é possível gerar um rico material que fale de permanências, em outras palavras, de um patrimônio que vem vencendo o tempo e se mantendo vivo graças à sua aderência ao uso cotidiano. Por outro lado, o patrimônio urbano do Estado de Alagoas apresenta timidez diante do reconhecimento patrimonial de outras regiões, inclusive vizinhas, como Sergipe e Pernambuco.

No material holandês, é possível observar detalhes do cultivo de alimentos, da construção da casa, do uso do carro de boi e das canoas para pesca etc., que, na pesquisa em tela, estão sendo confrontados com a prática vigente nas cidades estudadas. Por exemplo, observou-se a manutenção das várias etapas do processo da produção da farinha de mandioca, largamente comentada e registrada nas fontes holandesas e que chega aos dias de hoje, ocorrendo de forma muito semelhante ao que comentam as fontes históricas. Outro exemplo da longevidade das práticas e dos elementos paisagísticos refere-se ao cultivo de plantas e à presença de espécies. Assim, vários exemplares da flora registrados pioneiramente na obra de George Marcgrave e Guilherme Piso, são ainda evidentes nas paisagens alagoanas estudadas, a exemplo da Imbira, encontrada nas matas próximas à localidade do Pontal de Coruripe:

"Seu fruto é oval do tamanho de avelã; de sabor aromático e acre, podendo ser usado como pimenta seco e reduzido a pó. Tem uma grande força aromática; não tão acre como a pimenta. A casca separada da árvore serve para corda; é muito flexível; da mesma se fabricam estupins necessários para explosões. Quando se tira é branca; separando-se o fusco externo torna-se avermelhado, num quarto de hora" (PISO, 1958).

Acredita-se que o rastreamento dos aspectos materiais, mas também dos imateriais do recorte em estudo possa ampliar os acessos ao conhecimento histórico-cultural do lugar e, por extensão, criar alternativas para intervenções posteriores que visem a promoção do patrimônio local, através da reativação de suas cargas identitárias. Ativar memórias adormecidas através do levantamento documental não só contribui para o conhecimento do conteúdo patrimonial desses antigos núcleos, como também potencializa seus atributos atuais.

Ao aproximar fontes de registro histórico geradas pelas matrizes européias e o conhecimento extraído do cotidiano das comunidades, coloca-se em contato as vertentes erudita e popular no ensejo de que, juntas, ganhem um outro viço, enriquecendo-se mutuamente e criando condições de inclusive, serem disponibilizadas para além do cenário nacional. Rastrear informações acerca da história nordestina através do fragmento territorial alagoano, é referir-se às primeiras expressões culturais brasileiras resultantes da experiência compartilhada de europeus e nativos. Como numa via de mão dupla, aproxima a "terra virgem" colonizada (Brasil) e a empresa colonizadora (Portugal, Países Baixos, Espanha), impressas na paisagem.

Ao atentar para os aspectos do cotidiano, os fazeres e saberes são convocados a contribuírem para um conceito de paisagem que se quer colado à existência humana. Tal qual em outro contexto, outras imagens holandesas, produzidas no mesmo período áureo da arte nórdica nos seiscentos, retrataram os mais prosaicos atos da existência dos seus cidadãos, e assim se 
constituíram em um dos berços do próprio conceito de paisagem dentro do contexto da cultura ocidental, aliando arte e identidade 5 .
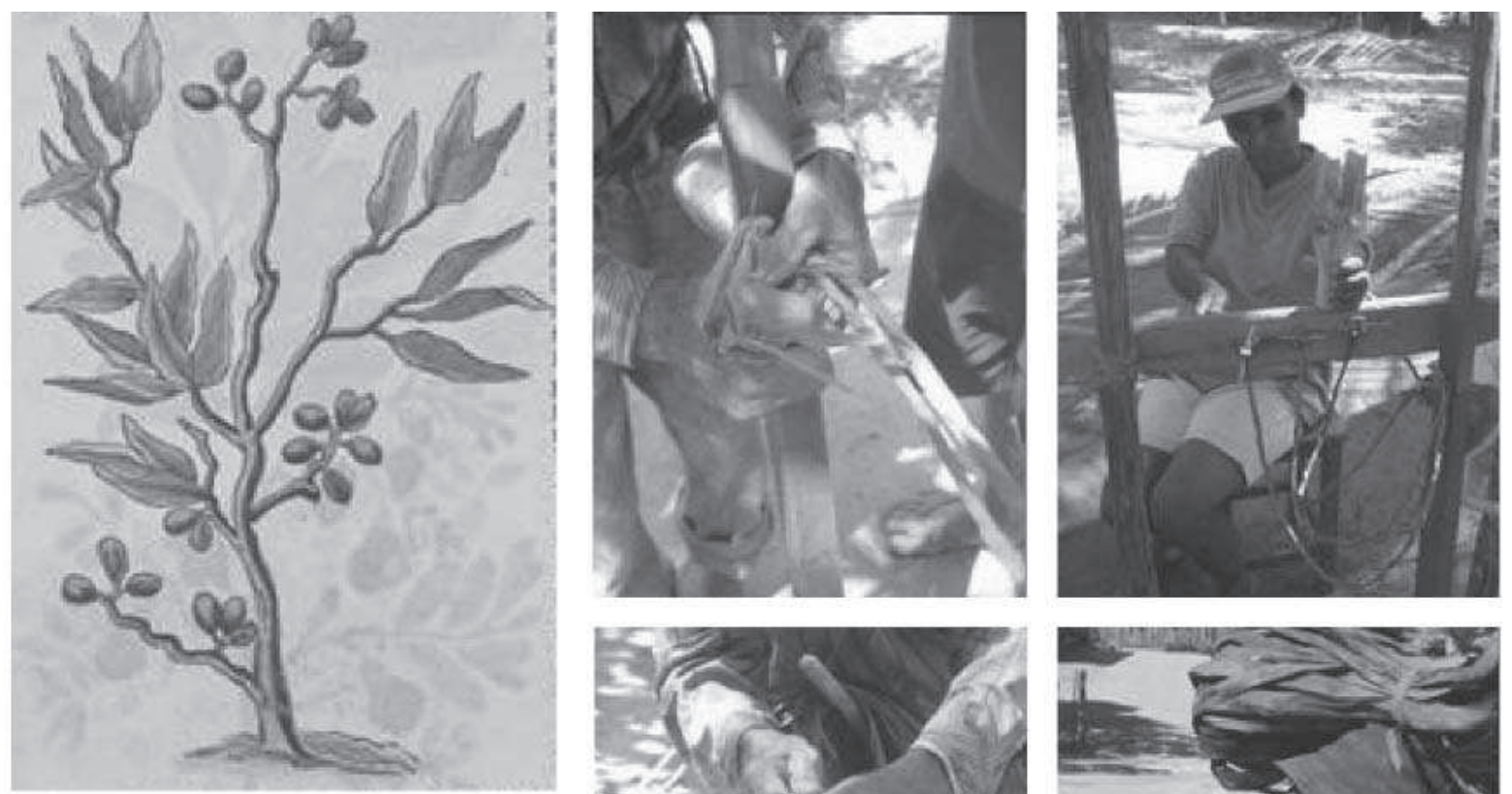

Desenho da Imbira, registrada por MARCGRAVE (1942, p. 99), utilizada pelos moradores da comunidade (ao lado) como matéria-prima para o feitio de corda destinada a usos diversos

Fonte: Arquivo do Grupo de Pesquisa Estudos da Paisagem
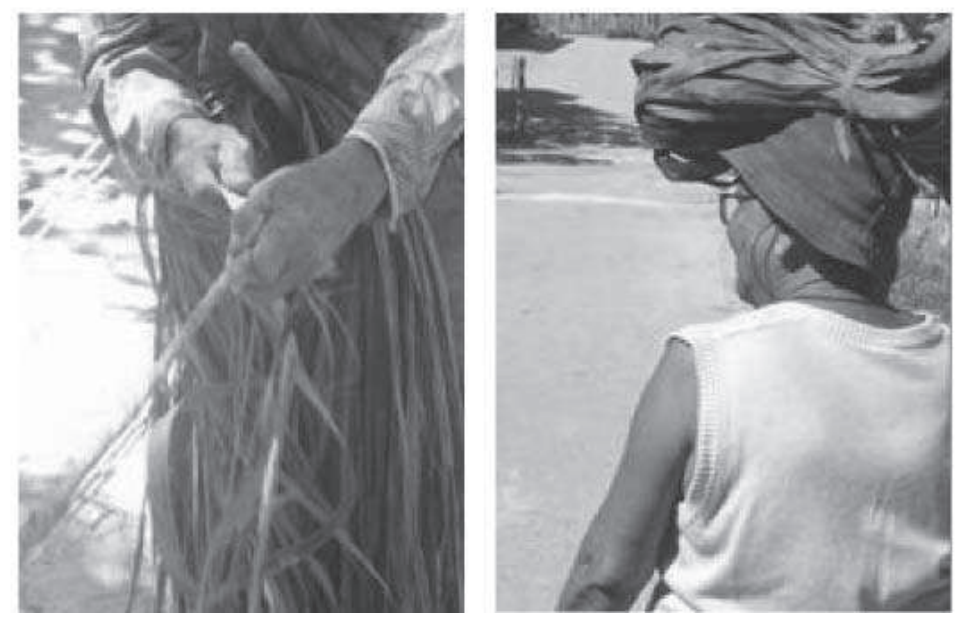

\section{Patrimônio paisagístico: entre o material e o imaterial}

O crescente interesse que as fontes holandesas, especialmente as imagéticas, vem despertando, como atestam suas recentes publicações, e as inúmeras possibilidades que oferecem, dentro das mais diversas disciplinas como os estudos botânicos, zoológicos, históricos e antropológicos, nos trazem a idéia de que tais estudos se enriquecem à medida em que os saberes se aproximam. Os encontros interdisciplinares, portanto, animam os conteúdos destas fontes. No caso deste projeto, além da interdisciplinaridade, alimenta-se do diálogo entre as fontes eruditas e as vernáculas.

Pretende ainda apresentar alternativas de futuro para velhas paisagens, na medida em que os dados, extraídos através do levantamento oral, textual e iconográfico, realizado através de um diálogo que aproxima o passado e o presente, sejam disponibilizados para o trabalho de instituições governamentais, no contexto da gestão educacional, cultural e turística.

Através de uma ressignificação do local, seus resultados também podem incentivar um balanço sobre as perspectivas das comunidades estudadas frente à estimativa de um presente e um futuro globalizados, onde, cada vez mais, configuram-se de suma importância os trabalhos de reconhecimento da identidade e da memória dos grupos sociais, particularizados no patrimônio material e imaterial. 
Sobre os conteúdos imateriais, cuja importância vem sendo defendida com mais ênfase nos últimos anos pelo Instituto do Patrimônio Histórico e Artístico Nacional, eram recomendados por Mário de Andrade na década de trintaf. Embora declinados á época, hoje são relembrados pela instituição.

Mas este patrimônio também enriquece a discussão sobre o tema da paisagem, à medida que convoca outros ingredientes, muitas vezes negligenciados por arquitetos, urbanistas e paisagistas, para a compreensão mais completa do cenário da vida dos homens e do legado que deixam à posteridade. Este é o convite que a comunicação ora apresentada busca trazer.

\section{Notas}

(1) Pautamos este conceito na obra de autores como Augustin Berque. Ver bibliografia.

(2) Antes de difícil acesso, restritos aos trabalhos pioneiros de José Gonsalves de Mello e outros, atualmente os acervos textuais e imagéticos holandeses têm sido disponibilizados através de inúmeras iniciativas. Podemos citar a Coleção Brasil-Holandês da Editora Índex que contou com o patrocínio da Petrobrás e ainda os catálogos que acompanharam as exposições intituladas "O Brasil e os Holandeses" e "Eckhout retorna ao Brasil".

(3) As discussões apresentadas nesta comunicação respaldam-se no projeto Modos de construir, modos de alimentar: memórias da paisagem Caeté das Alagoas, que vem sendo desenvolvido pelo Grupo de Pesquisa Estudos da Paisagem-UFAL, sob a coordenação da prof. Maria Angélica da Silva, com financiamento do IPHAN.

(4) O Grupo, registrado na base do CNPq desde 1992, vem realizando suas pesquisas com as fontes holandesas com o apoio da FAPEAL, Fundação de Amparo à Pesquisa do Estado de Alagoas, do CNPq e da CAPES.

(5) Sobre este tema, ver as duas obras de Simon Schama apresentadas nas referências bibliográficas.

(6) Ver o ante-projeto apresentado por Mário de Andrade, solicitado por Rodrigo Melo Franco de Andrade, no contexto da elaboração do Decreto Lei que regeria a atuação do Serviço do Patrimônio Histórico e Artístico Nacional.

\section{Bibliografia}

ALCIDES, Melissa Mota. História Naturalis Brasiliae: Um estudo do registro botânico holandês seiscentista. 2005. 153p. Dissertação (Mestrado) - Departamento de Arquitetura e Urbanismo, Universidade Federal de Alagoas - Dinâmicas do Espaço Habitado, Maceió, 2005.

ALPERS, Sveltana. The art of describing - Dutch art in $17^{\text {th }}$ century. Chicago: Penguin Books, 1983.

BARLAEUS, Gaspar. História dos feitos recentemente praticados durante oito anos no Brasil. São Paulo; Belo Horizonte: Edusp/Itatiaia Ed., 1977.

BRASIL-HOLANDÊS. Miscelânea cleyeri, libri principis \& theatrum rerum naturalium Brasiliae. Rio de Janeiro: Índex, 1995.

Theatrum rerum naturalium Brasiliae. Rio de Janeiro: Índex, 1995.

Niedenthal, animaux et oiseaux \& naturalien-buch. Jacob Wilhelm Griebe. Rio de Janeiro: Index, 1998. (Coleção de Jacob Wilhelm Griebe).

Documentos da biblioteca universitária de Leiden, o Thierbuch e autobiografia de Zacharias Wagener e os quadros do Weinbergschlösschen de Hoflössnitz. Rio de Janeiro: Índex, 1997.

Index, 1998

O diário de viagem de Caspar Schmalkalden de Amsterdã para Pernambuco no Brasil. Rio de Janeiro:

Theatrum rerum naturalium Brasiliae. Rio de Janeiro: Índex, 1993.

BERQUE, Augustin. Écoumène - Introduction à l'etude des milieux humains. Paris: Belim, 2000.

et al. Cinq propositions pour une théorie du paysage. Seyssel: Champ Vallon, 1994

BRANDÃO, Théo. Folguedos natalinos. Maceió: Museu Théo Brandão/UFAL, 2003. 
BRANDÃO, Théo. Catálogo da correspondência passiva de Théo Brandão. Maceió: Museu Théo Brandão/UFAL, 1995.

CASCUDO, Luís da Câmara. Antologia do folclore brasileiro. São Paulo: Global, 2002.

ECKHOUT VOLTA AO BRASIL 1644-2002: Catálogo da mostra. São Paulo: Pinacoteca do Estado de São Paulo, 2002.

FITCH, James Marston (Orgs). Historic preservation - Curatorial management of the built world. Londres: University Press, 1995.

FREIRE, Gilberto. Casa grande e senzala: formação da família brasileira sob o regime da economia patriarcal. São Paulo: Global, 2004.

Sobrados e mucambos. São Paulo: Global, 2004.

HERKENHOFF, P. (Org.) O Brasil e os holandeses, 1630-1654. Rio de Janeiro: Sextante Artes, 1999.

MARCGRAVE, George. História natural do Brasil. São Paulo: Imprensa Oficial do Estado de São Paulo, 1942.

REIS FILHO, Nestor Goulart. Imagens de cilas de cidades do Brasil colonial. São Paulo, Edusp, 2000.

PEDROSA, Tânia de Maya (Orgs.). Arte popular de Alagoas. Maceió: Grafitex, 2000.

PISO, Guilherme. História natural do Brasil ilustrada. São Paulo: Companhia Editora Nacional, 1958.

SCHAMA, Simon, Landscape and memory. Londres: HarperCollins Publishers, 1995.

. The embarrassment of riches - An interpretation of dutch culture in the golden age. Londres: HarperCollins Publishers, 1988.

TEIXEIRA LEITE, J. R. A pintura no Brasil holandês. Rio de Janeiro: Edições GRD, 1967. 